University of Rhode Island

DigitalCommons@URI

Open Access Master's Theses

1976

\title{
Hypnotic Susceptibility of Undergraduates: Class Standing, Major, and Sex
}

Randall B. Plourde

University of Rhode Island

Follow this and additional works at: https://digitalcommons.uri.edu/theses

\section{Recommended Citation}

Plourde, Randall B., "Hypnotic Susceptibility of Undergraduates: Class Standing, Major, and Sex" (1976). Open Access Master's Theses. Paper 1552.

https://digitalcommons.uri.edu/theses/1552

This Thesis is brought to you for free and open access by DigitalCommons@URI. It has been accepted for inclusion in Open Access Master's Theses by an authorized administrator of DigitalCommons@URI. For more information, please contact digitalcommons-group@uri.edu. 
HYPNOTIC SUSCEPTIBILITY OF UNDERGRADUATES:

CLASS STANDING, MAJOR, AND SEX

BY

RANDALL B. PLOURDE

MASTER'S THESIS SUBMITTED TO THE PSYCHOLOGY

DEPARTMENT IN PARTIAL FULFILLMENT OF

THE REQUIREMENTS FOR THE DEGREE

OF MASTER OF ARTS

IN

PSYCHOLOGY

UNIVERSITY OF RHODE ISLAND

1976 
There never was a truth, Nor a mind to conceive it. Fundamentally, not one thing exists, So where is the dust to cling?

Adapted from Hui-neng (638-713 A.D.) The Sixth Patriarch, Zen Buddhism 


\section{ABSTRACT}

The present study is basic research designed to investigate the relationships among the variables of class standing, major, and sex and the hypnotic susceptibility of undergraduate students. The results were also to be assessed for indirect indications of a relationship between age and HS and for indirect indications of an increase in HS of undergraduates as a result of contemporary trends such as the popularization of mind altering chemicals. From a pool of over 1,200 volunteers recruited from University of Rhode Island classrooms, 240 undergraduate participants were selected on the basis of specified criteria. The Harvard Group Hypnotic Susceptibility Scale: Form A, in tape form, was used as the measurement procedure. A three-way analysis of variance, with an a priori significance level of .05 , was used. No significant differences were found for HS across class standing or for social science and natural science majors. A significant difference between male and female hypnotic susceptibility was found; mean for males $=6.66, \mathrm{~S} . \mathrm{D} .=2.61 ;$ mean for females $=7.16$, S.D. $=2.78$. There were indirect indications that there might be stabilization in HS for the participants between the ages of 17 and 22, and there were no clear indications of an increase in HS of undergraduates. The meaning of the results is discussed; no solid conclusions are drawn, and more basic research is called for. 


\section{ACKNOWLEDGMENTS}

My appreciation is extended to Dr. Stanley I. Berger for sharing his viewpoints, for providing encouragement to pursue this research, and for his support during the difficult times which intervened prior to putting the results into writing. And my thanks to Dr. Peter F. Merenda who is responsible for assuring that the basic research design and statistical analysis were sound. It is unfortunate that Dr. Damian P. Fedoryka of the Philosophy Department was unable to see the entire process through to the end; my wish is that he will be gratified in his new position at the University of Dallas. When he left the University, Dr. Wayne F. Velicer kindly became a part of the committee and has been helpful in clarifying issues. Dr. Fritz Wenisch, also of the Philosophy Department took me aback with his unsolicited offer to fill the open place on the committee; I am very grateful. And thanks goes to Dr. Ralph W. England of the Sociology Department for offering his time and energies to chair the defense committee. And without a reference made here, the participation of my wife Cynthia, as an assistant, a critic, a typist, and a helpmate and friend would go unrecorded. 
TABIE OF CONTENTS

ABSTRACT..........................................

ACKNOWLEDGMENTS...................................

LIST OF TABLES..................................

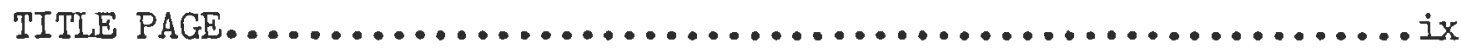

INTRODUCTION.......................................

CHAPTER I HYPNOTIC SUSCEPTIBILITY: UNDERGRADUATE

CLASS STANDING, MAJOR, SEX, AND OTHER

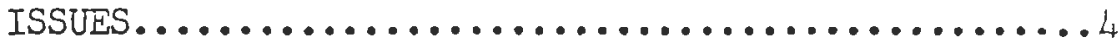

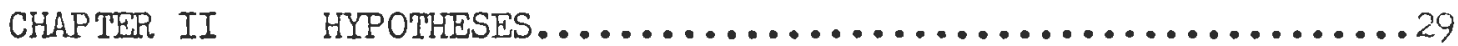

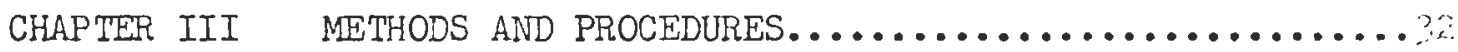

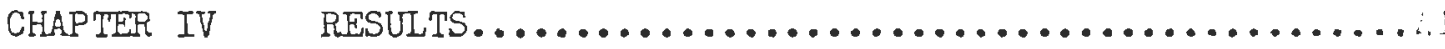

CHAPTER $V$ DISCUSSION OF THE RESULTS.................44

CHAPTER VI CONCLUSIONS.........................

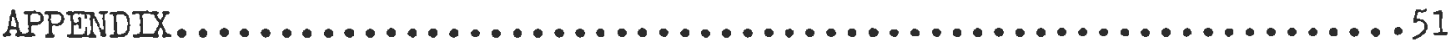

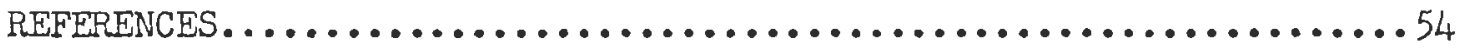




\section{LIST OF TABLES}

TABLE

1. Analysis of Variance for Hypnotic Susceptibility.........42

2. Mean HS Scores and Standard Deviations For

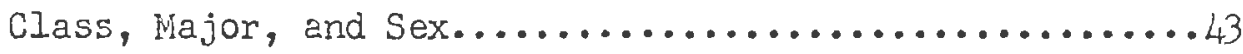


HYPNOTIC SUSCEPTIBILITY OF UNDERGRADUATES:

CLASS STANDING, MAJOR, AND SEX 


\section{INTRODUCTION}

The orientation of this research follows the traditional conceptions of hypnosis as exemplified in the works of scientists such as Weitzenhoffer (1953, 1957), E. Hilgard (1965), and J. Hilgard (1970). This frame of reference distinguishes among means of bringing about hypnotic experiences, susceptibility to hypnotic experiences, and the depth or degree of hypnotic experiences.

Traditional theory holds that hypnosis can occur progressively from slight to marked, and that certain types of hypnotic experiences common in Western cultures reflect this progression. For example, eye closure often occurs when a person is at least slightly hypnotized, whereas hallucinations are considered to reflect marked hypnosis. This progression is referred to as depth or degree.

Whether every person has the ability to experience hypnosis or not, provided the right set of conditions are available, has been open to question. But what is clear is that some people are unable to experience hypnosis under certain conditions. These people would be said to lack hypnotic susceptibility under those conditions; they would not be able to experience even the slightest depth or degree of hypnosis. People who are able to experience some depth or degree of hypnosis are deemed to have hypnotic susceptibility. Hypnotic susceptibility, the focus of this research, is a term which is used to embrace the ability to have hypnotic experiences to some depth or degree. 
When hypnotic susceptibility is applied to standardized research conditions, this writer accepts the lead of $\mathrm{E}$. Hilgard (1965): "For assessment purposes we may define susceptibility as the depth achieved under standard conditions of induction, the more susceptible becoming more hypnotized than the less susceptible when common procedures are followed."

One of the most common ways of bringing about hypnotic experiences is through the use of verbal suggestions in situations clearly defined as intending to induce hypnosis. Such suggestions would be deemed 'hypnotic' suggestions, and they continue to be researched extensively. Another approach to bringing about what traditionally have been considered hypnotic experiences has been through the use of verbal suggestions in situations in which any reference to hypnosis is intentionally avoided and no attempt is made to put participants into an hypnotic state (Barber and Calverley, 1963). Such suggestions are called 'waking' suggestions. Research from each of these approaches will be discussed, and the reader is asked to keep in mind the dislinction betwcen 'hypnotic' and 'waking' suggestions.

The present research explores basic variables common to undergraduate student populations such as class standing, major, and sex while controlling to some degree other important variables such as age, nationality, race, and marital status. It is important that scientists fully investigate these basic variables, since an enormous amount of contemporary research on hypnosis continues to be done with undergraduate students as the participants.

A thorough understanding of assessment procedures and the variables that are related to hypnotic susceptibility is necessary 
for practical applications; such as in screening people to determine whether or not they are readily able to experience slight, moderate, or marked degrees of hypnosis. This information can be useful in determining whether or not they might require tailored, individual approaches. Screening procedures might be useful medically in selecting patients for surgery without anesthesia, for pre and post operative application of hypnosis to aid recovery, for pain control, and for childbirth. Screening procedures might also prove useful where hypnosis is used psychotherapeutically, or educationally, or for self-development and self-understanding.

[Please note that in order to conserve space, hypnotic susceptibility will be abbreviated as HS.] 


\section{CHAPTER I}

HYPNOTIC SUSCEPTIBILITY: UNDERGRADUATE CLASS STANDING, MAJOR, SEX, AND OTHER ISSUES

\section{Undergraduate Class Standing}

One of the basic variables upon which this research focuses is undergraduate class standing, and its relationship to the HS of undergraduate students. Are Freshpersons, on the average, equally as susceptible as Seniors? Are there differences in HS dependent on class standing? Do four years of college or university education effect HS? If there are differences among classes, in what direction? These are important questions to answer in their own right; and especially considering that much research dealing with HS takes place on college and university campuses, and the populations and samples used in research often include undergraduates with differing class standing.

A review of the literature on HS did not find any research that investigated the relationship between class standing and HS. This is somewhat surprising given the large amount of HS research which is being carried out using undergraduate participants. The research which does deal with undergraduates over the four years of college has looked at the age of the participants without consideration of class standing (J. Hilgard, 1970; Morgan and E. Hilgard, 1973). Age appears to be an Important variable in 1 S. Whether class standing is or is not an important variable in HS is uncertain; but whatever the case may be, the re- 
lationship of class standing to HS cannot be investigated without considering the issue of age.

\section{Age and the Development of Hypnotic Susceptibility}

Hippolyte Bernheim $(1884,1964)$ has recorded for us in his clinical text the results of the classic work done by Liébeault on age and HS during the latter part of the nineteenth century. Using methods unspecified by Bernhein (the methods were probably clinical and not standardized), Liébeault rated 1012 people across a wide range of age-grades for their ability to respond hypnotically. The cross-sectional data indicated the possibility that children were more susceptible than adults, and that people within the age range of 7 to 14 years showed the highest degree of HS.

It was not until the first part of this century that standardized laboratory research on the relationship between age and the response to verbal suggestions began. This original research and contemporary refinements of this type of research are concerned with the age and 'waking' suggestions rather than with age and 'hypnotic' suggestions (Messerschmidt, 1927, 1933a, 1933b; Hull, 1933; Weitzenhoffer, 1953; Stukat, 1958; Barber and Calverley, 1963). Messerschmidt's (1933a, 1933b) cross-sectional data showed that young boys had the highest scores for 'waking' suggestion between the ages of 6 and 8 years. Barber and Calverley (1963) found maximum responsiveness to 'waking' suggestions in a cross-sectional sample of 724 children and adults to be between the ages of 8 and 10 years, with no differences in the 14-22 year old range. These studies have been shown to be related to HS (E. 
Hilgard, 1965).

Research dealing directly with age and HS has begun only recently. London (1962, 1963), and Moore and Lauer (1963), using small samples did not find significant differences in HS across ages. But when a larger cross-sectional sample was used $(\mathrm{N}=240)$ a distinctive pattern appeared. HS was highest between the ages of 9 and 14 years and was lowest between the ages of 15 to 16 years (London, 1965).

J. Hilgard (1970) has reported cross-sectional data from the Stanford Laboratory on the HS of undergraduate students ranging in age from 17 to 22 years that indicated a steady and statistically significant 'decline' in HS over the four years of college.

The research relating age and response to 'waking' suggestions, and age and HS has indicated that there might be a general developmental pattern across age-graded groups. The possible pattern is an increase in HS to a peak roughly between the ages of 8 to 14 years with either a decline and stabilization, or a gradual continuous decline thereafter. The literature has come to speak of the hypothesis of an age-related developmental pattern as an established fact.

Although clinical data, work with 'waking' suggestions, and work with 'hypnotic' suggestions do lend support to the hypothesis, more well-designed cross-sectional studies, as well as longitudinal studies appropriately controlled for practice effect, are necessary before the hypothesis can be considered fully supported. However, there is enough supporting evidence for the hypothesis of an age related pattern that the hypothesis be taken seriously in any research on HS in which significant age differences occur among the participants. Such is the case 
with this research on class standing.

\section{Undergraduate Major and Hypnotic Susceptibility}

Unlike class standing, a literature search turned up two researchers who have generated data on undergraduate major and HS. J.HIIgard's (1970) extensive work on personality and HS included evidence relating undergraduate major and HS. Her results supported the hypothesis that students' HS was related to the student's major area of study. The research found that there were significant differences in the HS levels of humanities majors, social science majors, and natural science majors, as measured by the Stanford Hypnotic Susceptibility Scale: C (Weitzenhoffer and E. Hilgard, 1962; further references will be abbreviated SHSS:C). As a group, humanities majors showed higher HS than did social science majors, who in turn showed higher HS scores than did natural science majors. J. Hilgard believed that some of the crucial variables that differentiated a science major from a humanities major were the tendency for the science major to have an habitual criticalanalytical set which militated against being able to spontaneously go with their experience, and to have a relatively fixed reality orientation that was capable of deep absorption and attentiveness, but to a relatively restricted range of interest areas. The humanities majors were more likely to set aside the critical-analysis of the experience, to have a more imaginative reality orientation, to be more aesthetic and spontaneous, and to have more diverse interests. For individuals, J. Hilgard believed that each of these patterns could and did occur in all majors; and that the HS level associated with each psychological 
pattern appeared accordingly.

William Coe (1964), while attempting to further develop norms for the Harvard Group Scale of Hypnotic Susceptibility: A (Shor, 1962; further references will be abbreviated HGSHS:A), found a significant pattern in his results which showed a difference between science and dramatic arts majors, in the same direction as J. Hilgard's (1970) results.

\section{Sex and Hypnotic Susceptibility}

While there has been work on the relationship between sex and HS which goes back to the nineteenth century, the matter has not been resolved, and there are issues that are complicating a resolution.

While discussing Liébeault's data on sex and HS, Bernheim (1884) stated that contrary to the prevailing belief of the researchers and practitioners of the late nineteenth century, females as a group, were only slightly more hypnotizable than males; and that the proportion of males to females that could achieve the highest levels of HS was only slightly in favor of females. In conjunction with his clinical experience, Bernheim used Liebeault's data to support his hypothesis. From a sample of 1012 people, Liébeault found that $18.8 \%$ of the males and $19.4 \%$ of the females were capable of the highest levels of HS.

In the twentieth century, a study of English school children (Aveling and Hargreaves, 1921-22), found females to have a 63\% positive response to suggestions while males had a $33 \%$ positive response. The differences were considered a function of the differential teaching and disciplinary practices. Clark L. Hull (1933) summarized the then aveilable work on 'waking' suggestions and 'hypnotic' suggestions con- 
cerning sex differences. In a study of 'waking' suggestion carried out in his laboratory, it was found that the mean score for females was slightly higher than for males, but that the difference was not significant.

Hull mentioned a study by Liebeault which he re-analyzed statistically. The results showed females with a higher mean HS, but the difference was not significant. Hull pooled the data for analysis from two contemporary studies (Barry, Mackinnon, and Murry, 1931; Davis and Husband, 1931) and found that the mean HS was higher for females, but that the difference was not significant. Hull concluded that since the studies were all independent of each other, and the results were in the same direction, that females were slightly more susceptible to hypnosis than males. The lack of statistical significance was considered a limitation of the analysis, and the consistent direction of the results, not the lack of significance, was the important matter.

Weitzenhoffer (1953) reviewed the research during and since Hull's time, and found that most of it supported the contention that females were slightly more susceptible than males (Seashore, 1895; Brown, 1916; Otis, 1924; Cason, 1925; McGeogh, 1925; Lodge, 1926; Messerschmidt, 1933; Wegrocki, 1934; Friedlander, 1938; Roach, 1941). There were studies reported by Weitzenhoffer which did not find a difference (Eysenck, 1943; Manzer, 1945). Weitzenhoffer concluded that females were slightly more susceptible than males to 'waking' and 'hypnotic' suggestion.

This viewpoint held until the late 1950's and early 1960's. At 
this time serious efforts were being made to create more effective, standardized measurement procedures. Using the Friedlander-Sarbin Scale (Hilgard, 1965) as a point of departure, the Stanford Laboratory group created the Stanford Hypnotic Susceptibility Scale: A and B (Weitzenhoffer and Hilgard, 1959; future references will be abbreviated SHSS: A and B). It was soon followed by the Stanford Hypnotic Susceptibility Scale: C (Weitzenhoffer and Hilgard, 1962). And then two other adaptions appeared: the group adaption, the Harvard Group Scale of Hypnotic Susceptibility: A (Shor and Orne, 1962; Shor and Orne, 1963); and the children's adaption, the Children's Hypnotic Susceptibility Scale (London, 1963). None of the original normative studies found a sex difference. Although the nature of the samples could account for the results (small samples, unequal groups for age and sex, inadequate control on age), the results were uncritically incorporated into the body of the literature, and researchers began to act as if it were a fact that HS were the same for both sexes.

Those who doubt the existence of a sex difference in HS often refer to works such as Weitzenhoffer and Weitzenhoffer (1958), Cooper and London (1966), and Barber (1969). Using the original FriedlanderSarbin Scale, Weitzenhoffer and Weitzenhoffer (1958) attempted to design an effective study. Although the sample was probably large enough $(N=200)$, and half were hypnotized by a male and half by a female, there were problems: a random sample was not used, there were no controls for age, class, or any other basic variable. Most of the people were undergraduate students, but some were staff, graduate students, and special students. The results were reminiscent of earlier work. Fol- 
lowing the pattern of so many other studies, the total mean score for the females (5.36) was slightly larger than the total mean score for the males (4.22); but statistical significance was not obtained. However, the Weitzenhoffers concluded that "...although our investigation and earlier studies agree that such differences as have been observed are not statistically significant there is also remarkable agreement that a small difference is present such as to show women as being somewhat more suggestible... when such differences occur repeatedly in the same direction and of the same order of magnitude, the likelihood that this is a chance effect becomes appreciably decreased and one can hardIy deny its reality... it must be considered as supporting the general overall conclusion that women are probably slightly more susceptible to hypnosis than men." Those who use the Weitzenhoffer study to refute sex differences either differ with these conclusions or neglect to mention the conclusions at all.

An interesting study by Cooper and London (1966) has taken exception to the Weitzenhoffers' conclusions and assumed no sex differences for HS. Using 240 children, they did control for age. If there were other controls, they were not mentioned, how the sample was selected was not made known, and there were only 10 children per age-grade by sex. Means were reported for each age-grade, and for some reason total means for both sexes were not reported, an important piece of datur for this type of study. In the analysis of the differences in HS for sex, statistical significance was not reached, and it was concluded that there were no sex differences for HS between males and females. Although statistical significance was not achieved, the 
appearance of the 'classical pattern' as described by Weitzenhoffer and Weitzenhoffer (1958) did appear; a slight absolute difference between males and females, with females being higher. For example, in the age range of 5 through 16, there were 12 age-grades. For the objective scores, the females (10 per age-grade) scored slightly higher mean HS on 8 out of 12 age-grades; and for the subjective involvement scores, slightly higher on 7 out of 12 age-grades. The total mean HS per age-grade (objective plus subjective scores) were split; 6 higher for males and 6 higher for females. An interesting result that went unnoted was that paralleling the age range where it has been hypothesized that people will have their highest HS levels, the female mean HS levels for objective, subjective, and combined scores were slightly higher than for males.

Barber's (1970) work is also referred to as evidence that there are no sex differences is HS. In providing normative data for the Barber Suggestibility Scale (Barber and Calverley, 1963), Barber used a sample of 724 students ranging in age from 6 to 22 . He did not find sex differences. But this was a 'waking' suggestion situation, not a HS situation. The people were told that they were being tested for imagination. No attempt to hypnotize was made, and people were given relatively brief suggestions to carry out. All the people were required to participate; they did not volunteer. No controls other than age were reported. Appropriate means were not reported, so one could not look for the 'classical pattern.'

Cooper and London (1966) pointed out that "...the Stanford Laboratory has constantly lailed to find any sex differences in suscepti- 
bility (Hilgard, 1965)." But they neglected to mention that E. Hilgard (1965) of the Stanford Laboratory made it clear that he believed that "...some subtle sex differences will doubtless be discovered in time..."

To summarize, in the early nineteenth century, there was little doubt that females were much more susceptible to hypnosis than males. By the end of the century, data emerged which called that view into question. During the early part of the twentieth century, it was widely accepted that females were only slightly more susceptible to hypnosis than were males. In post liWII America, this view began to be seriously questioned, and a strong current was created that held an equality in HS for males and females.

However, there are studies which have found sex differences related to HS which are statistically significant. For example, Fischer (1963) showed results indicating that males had a negative relationship between the definiteness of their body image boundary and their HS level. This was not the case for females. But the small samples were unequal for males and females and did not have a significant difference in the total mean HS. Hilgard and Lauer (1962) found that there were items on the California Personality Inventory which discriminated in HS for males, but not for females. Boucher and Hilgard (1962) found the 'classical pattern,' but also found that females with a high expressed preference for hypnosis had a high HS level, and females with a low expressed preference for hypnosis had a low HS level. Expressed preference for hypnosis did not relate with HS levels for males. Melei and Hilgard (1964) also found that males' expressed at- 
titude toward hypnosis did not correlate with HS, while the expressed attitude of females did correlate significantly. And independently of the other studies, Rosenhan and Tomkins (1964) showed that the attitude of females was predictive of their HS levels.

Coe's (1964) work has found mean sex differences for HS. Coe was developing further norms for the HGSHS: A. He used a motley student sample (neither random nor selected) composed of undergraduates and graduates, with an age range from 17 to 49 , and he had unequal groups. But he did control for sex and major. Female dramatic arts majors (mean $\mathrm{HS}=8.00$ ) were significantly higher than male dramatic arts majors (mean HS $=6.41$ ) and male science majors (mean $=4.33$ ). Male dramatic arts majors were significantly higher than male science majors (mean HS $=4.33$ ). But female science majors (mean $=5.31$ ) were not significantly higher than male science majors nor higher than dramatic arts majors. Given the motley nature of the sample, it is possible that these results are spurious. Rhoades and Edmondston (1969) have also reported mean HS differences. Using the HGSHS: A with unequal age distributions (males $=14$, executives, mean age 34.92; females $=10$, housewives or students, mean age 27.90 ), they found a higher mean HS for females. But that could be a function of age, representing different populations, etc. Other significant mean HS scores for sex were reported, but there were sampling problems there as well.

We have evidence that can be used to support both differences and non-differences between the scores for HS. And we have the complication of the issue of the 'classical pattern.' It seems to the 
writer that resolving the issues around the 'classical pattern' might point the way to a resolution of this matter of sex differences. The so called 'classical pattern' might be the results of chance. It is to be expected that if there are in fact no sex differences for HS, the absolute measurements for males and females will vary from one study to the next, with females being higher in one study, and males being higher in another study; a simple factor of chance.

On the other hand, the 'classical pattern' might be the result of real sex differences in HS which do not reach statistical significance for a variety of reasons. One outstanding reason might be poor experimental design. This writer is not aware of any research on HS that has employed a random sample. And in the absence of random samples, most, if not all, of the research on HS uses either motley, volunteer samples (anyone who volunteers, with little or no regard for other variables such as age, class standing, major, ethnic background, social class, etc.) or the research uses motley, captive or coerced samples ( a professor who volunteers the class, participation in the study is a requirement of the course; and here again there is often little or no regard for possibly important variables). This kind of sampling and lack of control could obscure real and significant differences in HS between the sexes.

Added to design issues, is the problem of measurement itself. Hypnosis research with standardized procedures is young; although the relatively new assessment procedures developed at Stanford and Harvard are far superior to what we had before, they are still dependent on on experimenter observation and participant self-report and are subject 
to error. This unavoidable problem puts a premium on design and variable control. Although content or construct validity seems solid according to researchers of the traditional school, improvements in the reliability of the assessment procedures would be welcomed (Buros, 1965). However, in this writer's view, it seems likely that real improvements in the measurement of HS will have to wait for the development of new technologies that will allow us to measure directly the psycho-neurophysiological variables which account for HS. In this way, observer and participant error can be avoided.

If the 'classical pattern' is a chance factor, then continued research will show it to be so. If the 'classical pattern' is in effect a partial reflection of real sex differences which has been obscured by poor research design, and possibly augmented by the imperfections in present assessment procedures, then by improving the design of our research, we might expect to uncover sex differences, even without the ultimate in assessment procedures.

It is hoped that this research will help add data to the research pool that will eventually lead to a resolution of the matter of sex and HS.

\section{Other Issues and Hypnotic Susceptibility}

During informal discussions with Dr. Stanley Berger of the Psychology Department of the University of Rhode Island about the HS of undergraduate students as related to class standing, major, sex, and other variables, it was learned that he shared a notion with the writer, that if accurate, might have a bearing on the investigation of 
the above basic variables. Dr. Berger and the writer wondered if the HS of many undergraduate students was increasing due to certain contemporary social-psychological trends which were influencing many undergraduate students to be more open to new and altered ways of experiencing; trends such as the popularity of drug use, participation in consciousness raising groups, and interest in the Eastern religions. If the HS ability of many undergraduate students were increasing, would this be reflected in an investigation of class standing, major, and sex?

Dr. Berger had learned through correspondence with Arlene Morgan (1970) of the Laboratory of Hypnosis Research at Stanford University that we were not alone in suspecting a change in HS due to certain trends. The Stanford Laboratory of Hypnosis Research has for many years been researching hypnosis and has accumulated much data. Arlene Morgan enclosed an unpublished report (Morgan and Williams, 1970) on cross-sectional data collected from 1958-1969 on Stanford students enrolled in the introductory psychology course. She explained that although Stanford data had been characteristically lower than groups measured elsewhere, there was a relative change in results over the years. From 1958-1964, the mean HS for 533 students was 5.6 on the 12 point scale. For the 333 students measured between 1965 and 1969, the mean HS was 6.9. This was a significant difference. The instruments used were modifications of the individually administered Stanford Hypnotic Susceptibility Scale: Form A (Weitzenhoffer and Hilgard, 1959). The report also communicated data generated with the group-administered Harvard Group Scale of Hypnotic Susceptibility: Form A (Shor and Orne, 1962), an adaption of the SHSS. A similar trend was found. The mean 
$\mathrm{HS}$ in $1962-63(\mathrm{~N}=61)$ was 5.8 , and the mean HS in $1967-1969(\mathrm{~N}=255)$ was 7.1. Morgan and Willaims speculated that the increases in recent years might be due to the popularity of hypnotic-like experiences such as drug experiences, meditation, and sensitivity and encounter groups. They felt that it was then more acceptable to be hypnotized than it had been in past decades. They also wondered if HS might be increasing in other than the Stanford students, and they reported a mean HS of $7.7(N=185)$ for junior college students in 1968-69 using the HGSHS: A. If the preliminary Stanford data were reflective of actual changes in HS, and if the hypothesis that social-psychological trends were in part responsible for the changes, then the measuring devices (SHSS and HGSHS) take on new applications other than measuring HS; they might prove useful as barometers that could detect the occurrence of less than obvious effects of societal trends on the mind life of the people.

However, there are a number of cautions that need to be kept in mind in order to avoid attributing inappropriate meaning to the Stanford data. The data were cross-sectional, not longitudinal. The data were pooled from a variety of studies with different samples. Although standardized, the measuring instruments were different; modified versions of the parent instrument. Conditions of administration were different. These problems, although not necessarily invalidating the results of the Stanford studies, need be kept in mind.

In the correspondence of 1970, Morgan informed Dr. Berger that some longitudinal work had been done which supported the hypothesis of social factors keeping HS levels from following the hypothesized pattern of decline with age. 70 students with an age range from 18 to 22 
years were measured between 1958 and 1962, and again in 1970. There was no decline in HS over the 8-12 year interval.

Dr. Berger corresponded with Morgan again in 1971. Morgan (1971) relayed that the cross-sectional results reported by J. Hilgard (1970) showing lower HS for seniors than for freshpersons (mentioned above) had not been replicated. Although the new cross-sectional data showed freshpersons having higher HS scores, the differences were not statistically significant.

The writer corresponded with Morgan in 1971, and received a manuscript by Hilgard and Morgan (1971) of a study using gross crosssectional samples $(\mathbb{N}=1,232)$. The study did not show a statistically significant difference in IS scores over the college ages.

For the writer, the seeds were sown for the idea that HS ability of many undergraduate students might be on the increase while the writer was teaching in high schools of Southeastern New Hampshire during the late 1960's. At that time, the phenomenon of valuing and seeking out the intentional alteration of consciousness through the use of a wide range of psycho-active chemicals (marijuana, hashish, mescaline, cocaine, ISD, barbiturates, amphetamenes, etc.) had begun to establish a foothold within the middle class student subculture of the region and had begun to be an integral part of many students' life styles. Some students spoke freely with the writer about altered modes of consciousness (AMC) which they sought with such positive anticipation. Their descriptions of changes in their sense of perceptions, time sense, body awareness, emotional states, personal expressiveness, attitudes, etc. brought to mind the types of experiences that can occur hypnoti- 
cally. A review of some of the literature dealing with consciousness altering chemicals (Huxley, 1954, 1955; Watts, 1962; Alpert, Cohen, Schiller, 1966; Lindesmith, 1966; Masters and Houston, 1966; DeBold and Leaf, 1967; and Nowlis, 1969) further reinforced the notion of a phenomenological similarity, albeit arrived at through differing means, between chemically induced and hypnotically induced AMC. The construct of an apparent phenomenological similarity led to the proposition that perhaps repeated, positive experiences with chemically induced AMC might increase the receptivity to hypnotically induced AMC; that students who had had repeated positive experiences with chemically induced AMC would, on the average, be more susceptible to hypnotically induced AMC than they would have been prior to their chemical experience. Turning to the literature, it was found that there was early research which focused on the effects of certain chemicals on the response to suggestions and HS while the chemical was still active within the person's system. Hull (1933) noted that hypnotists have traditionally held that certain depressants were useful in potentiating the influence of suggestions for people who were refractory to hypnosis. Hull's own work on alcohol and HS ended prematurely, but he felt able to conclude that a slight increase in the effects of 'waking' suggestions did occur when alcohol was in the person's system. Hull summarized a study by Baernstein (1929) involving 19 medical students which showed that refractory students remained refractory, while responsive students became more receptive when scopolomine hydrobromide was in their systems.

Weitzenhoffer's (1953) review of the literature on the interac- 
tion of certain chemicals and hypnosis pointed out that meaningful amounts of experimental work had not yet been done, and that most of the work was clinical and descriptive in nature. The clinical studies contended that a variety of depressants increased a person's response to suggestions while the chemicals were active in their systems. In the absense of corroborating, controlled experiments, and on the basis of his own assumptions, Weitzenhoffer posited that certain chemicals did not create hypnosis or suggestibility, but they did facilitate HS by inducing ease and relaxation in the person. He cited a study by Vogel (1937) which indicated that people addicted to opium, morphine, and heroin, tended to have a hyper-suggestibility to the postural-sway test, a suggestibility which decreased with withdrawal. Weitzenhoffer concluded that the available evidence indicated that chemicals which induce sleep and dull pain did facilitate suggestibility while the chemicals were active in their systems, provided that the person started with a modicum of suggestibility. He is in agreement with Hull. More recentIy, Fogel and Hoffer (1962), studying one female who had ingested 100 micrograms of LSD-25, tried to neutralize the resulting AMC with hypnosis; but only slight change in the woman's experience was reported by her. E. Hilgard (1965) cited a then unpublished study by Sjoberg which produced results showing that, when in a person's system, LSD-25 and mescaline were agents capable of increasing responses to suggestions to an equivalent degree as did standardized induction procedures. E. Hilgard concluded that it is possible that certain chemicals can make a person unusually responsive to suggestions, thus agreeing with Hull and Veitzenhoffer. 
During 1969 and the early 1970's this writer worked as a residence hall director on two college campuses. While working and living within the college student subculture, the writer had constant involvement with students who often had various chemicals active in their systems. The chemical fad was in full swing, and often there were students who wanted to discuss their chemical experiences, or who were in need of immediate help due to the negative effects of a chemical. The writer's experience with hypnosis seemed to make it relatively easy for him to slip into the phenomenological Hell of a bad trip and talk a person down, as well as make it relatively easy to understand and relate to people's experiences of their chemically induced AMC.

The residence hall director experiences raised more questions and led back to the literature (Barber, 1970; J. Hilgard, 1970; Tart, 1969, 1971; Grinspoon, 1971; and Baudelaire, 1971). Barber (1970) concluded on the basis of only two studies (Levis and Mehlman, 1964; Fogel and Hoffer, 1962, mentioned above), that although influential, the suggestions from an experimenter may not be as potent in effecting the AMC induced with psychedelics as had been thought, and that if experimenters were friendly and relaxed with the people they were working with, the people showed little anxiety; but if experimenters were impersonal, hostile, or had an investigative attitude, they were likely to elicit anxiety, hostility, or paranoid-like responses. Tart (1971), himself a researcher in hypnosis, did an extensive study of marijuana intoxication, a study of historical significance in that it was the first federally supported study to explore what users gain from smoking marijuana. He reported that a minority of people intentionally use hypnosis to poten- 
tiate the effects of marijuana. None reported using marijuana to potentiate hypnosis. Tart's earlier edited work (1969) indicates through logical inference a distinct phenomenological similarity between chemical AMC and hypnotic AMC; as does Weil's (1972) discursive text which deals with a cornicopia of AMC. J. Hilgard's (1970) in-depth study of personality and hypnosis only touches on chemicals, since the fad had not taken root when the interview portion of the study was done. But she did see fit to mention Clifford, who she believed represented the then small chemical-group participating in her research. She thought it worthwhile to report that from Clifford's experiential vantage point, he believed that "hypnosis is the breaking point between the standard way of perceiving and the way of ether and mescaline." Hilgard's research indicated that those she termed "mental space travelers," a category in which Clifford was placed, were high scorers on HS tests, and that "mental space travelers" had interests in hypnosis and some interest in chemicals.

Just prior to carrying out the present study, the work of David Van Nuys (1972) of the University of Michigan became known (manuscript submitted in 1970). It appeared that he was the first to report HS data on persons who had experienced chemically AMC, but who had not as far as he could tell, taken the chemical immediately prior to the measurement of their HS. Van Nuys asked for a self-report of the person's (male undergraduates) estimated degree of use of marijuana or hashish and the degree of use of psychedelics. Following the self-reports, their HS was measured (HGSHS: A). Those who reported use of some form of cannabis or psychedelic had significantly higher mean HS scores than 
did those who reported non-use. These results were a fractional part of a larger study designed to explore HS and individual differences in attention. The study was not intended to uncover causal relationships. However, there are researchers who have raised issue with the modifiability of HS and have concluded that HS is an enduring ability that is relatively stable. Gill and Brenman (1959) have reported their surprise at the relative constancy of HS for people they had hypnotized. They came to expect that those who initially had a low HS remained low, as those with a moderate or high HS remained at their initial levels. Covering all the people Gill and Brenman have worked with throughout their careers, they encountered no more than a dozen instances of significant alterations in HS; and these were considered to be spontaneous alterations. They interpreted changes in $H S$ as defensive reactions to an upsurge of hostility and/or passive-dependence in the person's relationship with the hypnotist. The orientation of Gill and Brenman is psychoanalytic, which is considered by the writer to embrace an unrealistically conservative attitude toward significant psychological changes in people. It is possible that the results of their clinical work were a function of their expectancies, which were tied to their theoretical orientation.

As, Hilgard, and Veitzenhoffer (1963) interpreted their laboratory results as verifying the relative stability of hS, concluding that although HS can be changed within certain limits, dramatic changes will generally not take place. They did not focus on what they believed accounted for the notable gains in HS which did appear for some of the people in the study. E. Hilgard (1965) has postulated that a researcher 
might fall prey to the illusion that a person being trained in the hypnotic experience is expanding his HS, when in actuality the person is only increasing the speed with which the hypnotic experience evolves. The work of Shor, Orne, and O'Connell $(1962,1966)$ has been reported as corroborating the stability hypothesis (E. Hilgard, 1965; Tart, 1969). However, at the April, 1964 convention of the Eastern Psychological Association, the tentative findings of Cobb's and Shor's then recent work were presented. They believed that they had found that HS could increase beyond plateau levels by using non-traditional procedures such as prolonged sensory-isolation. Shor and Cobb (1968) have presented other findings that seem to demonstrate the possibility of altering a person's HS. They hypothesized that an important factor in training is meeting the person's needs and expectancies, and that if this is not done, a sound and trusting relationship necessary for guiding a person into the hypnotic experience is hard to develop. Shor and Cobb found that five of the eight people they worked with did show meaningful, quantifiable changes beyond their pre-training plateau, and that some of the important changes clearly evident to the researchers were not completely reflected in the standardized scoring. The three people who were not as receptive to altering their HS, and who showed no changes beyond their pre-training plateau, did report alterations in their inner experience which indicated to Shor and Cobb that the training did have meaningful effects even for the three non-receptive people (in particular, sensory-isolation training). Wickramsekera (1969) also found that sensory restriction increased HS. Milton Erickson, using unusually creative and effective hypnotherapy and dealing with the vast array of miseries to which humankind 
is susceptible, has long since anticipated the results of Shor and Cobb (Haley, 1967). For decades Erickson has been stressing that the sensitivity, the creativity, the ability to relate, and the common sense of the hypnotist are the crucial variables for developing, maximizing, and maintaining HS. And he is critical of the researchers who generate results with inadequate or misused hypnotic procedures, be they individualized or standardized. From Erickson's writings, it is reasonable to infer that for him the alteration of HS is essentially an issue only to the extent that the hypnotist has the ability to relate to the unique psychological set of each person in such a way that will allow for alteration in HS.

Pascal and Salzberg (1959) using an extensive induction procedure which did not scrimp on the time allotted for each person, produced results considerably different from those usually reported for HS. They found that $56 \%$ of the people $(\mathrm{N}=52)$ were brought to high levels of HS within one session. Wiseman and Reyher (1962) using a different but extensive and involving procedure also produced unusually high levels of HS as well as considerable changes in HS. They were able to bring $33 \%$ of the people they worked with to unusually high levels of HS. And after using a dreaming procedure, $70 \%$ of the people reached high levels of $\mathrm{HS}(\mathbb{N}=30)$.

Sachs and Anderson (1967) using standardized scoring procedures (Stanford Hypnotic Susceptibility Scale: A and C) with a training technique that had a standardized approach, which was applied in an individualized manner to meet the needs of the person, found statistically significant changes in HS. They posited the hypothesis that increases in HS were a function of appropriate training techniques. Sanders and Reyher (1969) found that sensory deprivation brought positive 
changes in HS, but mainly for those who were initially high in HS. Cooper, Banford, Schubot, and Tart (1967) turned up results which they believed were in line with the hypothesis that people with originally high HS profit more from training, but that only slight gains were to be expected. Tart (1969) has since altered his position and now hypothesizes that changes in HS are very much a function of the procedure used. He has further hypothesized that using a method of mutual hypnosis which involves a two-way rapport enhances HS.

Barber and Calverley (1966) tested Hull's (1933) postulate that HS is a habit phenomenon and found that repeated standardized suggestions decreased the person's HS. They simply became bored and disinterested. Barber and Ascher (1971) have redone the study using diverse suggestions rather than repetition and found that HS can be increased. By attempting to keep the person's interest and prevent boredom, HS was altered in a positive direction.

The long experience of clinicians has led most to believe that HS is meaningfully modifiable within a given age-grade. But only through recent efforts have laboratory researchers begun to find appropriate procedures which allow for a standardized and quantifiable demonstration that alterations in HS can indeed occur within a given age-grade in degrees that are meaningful. This raises a question pertinent to the present study. If HS within a given age-grade can intentionally be altered, can it also be altered within a given agegrade by an unintentional, naturalistically occurring cluster of social-psychological factors? Based on the assumptions underlying the present study, the suspected answer was yes; that HS could be uninten- 
tionally altered as a result of a cluster of social-psychological factors occurring naturalistically as a part of a person's general life style.

This brings us full circle and returns attention to the factors of class standing, major, and sex. In the exploration of these variables relative to the HS of undergraduate students, a number of matters need to be kept in mind. In the absence of a random sample, a premium is placed on controlling as many variables as is practical under the Iimitations of the resources that are available for the study. Given what evidence we have regarding age, it seems to be a factor which must be controlled in some manner. Another factor which might be of some importance in designing the research or interpreting the results is a possible increase in the HS of many undergraduate students as a result of naturalistically occurring social-psychological trends; such as the popular use of consciousness altering chemicals that provide an experience which can be phenomenologically similar to experiences induced via hypnosis. 
CHAPTER II

HYPOTHESES

\section{Class Standing}

Previous research hints that we might look for a progressive decline in HS across class standing from Freshperson to Senior ( $J$. Hilgard, 1970). Other research, based on results from work on 'waking' suggestions across age-grades that parallel the age-grades common to different class standings, suggests the possibility of no changes occurring across the classes (Barber, 1963).

Due to the problems of (1) being unable to find any previous research on class standing and HS, (2) having to rely on age related research as a guide, and (3) the age related research being limited, (4) having design problems, and (5) lacking replication, it is not possible to posit with certainty an expected direction that the relationship between class standing and HS might take. But it does seem probable that the relationship will follow a pattern that the developmental hypothesis suggests. A possible pattern is a decline in HS across class standing. Another possible pattern might reflect a stabilization of HS whereby no differences across class standing would appear.

However, there might be other factors operating to influence HS across class standing; contemporary social-psychological trends such as the popular use of consciousness altering chemicals might have the 
effect of increasing the HS of many undergraduate students. If this is occurring, the results might be effected in unexpected ways, and we might see results across class standing which deviate from a pattern suggested by the developmental hypothesis; or if the pattern is uneffected, the absolute level of HS might be unusually high. Since it is expected that the relationship between class standing and HS will be effected by social trends like the popularity of drug use, the hypothesis for class standing is the following:

Hypothesis I: Hypnotic susceptibility is related to the class standing of undergraduate students (in such a way as to deviate from a progressive decline over the four classes; or if there are no differences across classes, the absolute level will be unusually high).

\section{Major}

It is expected that the pattern between major and HS will reflect the results of previous studies (Coe, 1964; J. Hilgard, 1970); creative arts students will have a higher HS level than social science students, who will in turn have a higher HS level than natural science students.

Hypothesis II: Hypnotic susceptibility is related to the major of the student (creative arts students will have higher HS levels than social science students, who in turn will have higher HS levels than natural science students). 
$\underline{\operatorname{sex}}$

In accord with the classical position, it is expected that females will have a slightly higher HS level than will males. Hypothesis III: Hypnotic susceptibility is related to the sex of the student (females will have slightly higher HS levels than will males).

\section{Interactional Hypotheses}

Following the lead of coe (1964), it is inferred that if the above hypotheses are supported, there will be an interaction in a direction consistent with that of hypotheses I, II, and III. For example, the Senior creative arts major females will have a higher HS level than will the Freshperson natural science major males. Hypothesis IV: Hypnotic susceptibility is related to the interaction of class standing and major of the student (in the direction indicated above).

Hypothesis V: Hypnotic susceptibility is related to the interaction of class standing and sex of the student (in the direction indicated above).

Hypothesis VI: Hypnotic susceptibility is related to the interaction of major and sex of the student (in the direction indicated above). Hypothesis VII: Hypnotic susceptibility is related to the interaction of class standing, major, and sex of the student (in the direction indicated above). 
CHAPTER III

METHODS AND PROCEDURES

\section{Criteria For Participation}

A premium was placed on maximizing control and having the largest possible N. Since a number of research efforts have supported the contention that volunteers and non-volunteers showed different characteristics and had differing mean HS levels (volunteers tended to be significantly higher), a volunteer sample was used to increase control (Martin and Marcuse, 1957; Brady, Levitt, and Lubin, 1961; Zamansky and Bright, 1962; Boucher and Hilgard, 1962; Levitt and Lubin, 1962; Bentler and Roberts, 1963). Once this basic decision was made, other criteria for participation were established to assure as much control as possible. The criteria for participation were the following:

1. Volunteers.

2. University of Rhode Island undergraduates.

3. Continuous enrollment since freshperson year.

4. Specific age-grade per, class: freshperson: 18-19; sophomore: 19-20; junior: 20-21; senior: 21-22.

5. A declared major in the creative arts (such as painting, sculpture, film, drama, music); social sciences (such as anthropology, sociology, psychology); and natural sciences (such as chemistry, physics, geology, biology, botany, bacteriology). 
6. For those who had not yet declared a major, an anticipated major in one of the three areas.

7. Never married.

8. Natural born citizen.

9. Caucasian.

It was plamed to allow anyone of any race to participate in the procedures. The booklets for non-caucasians would unobtrusively be removed from those which would be analyzed. However, since all the participants who met all the criteria for the research and came to the measurement sessions were caucasians, the procedure was not necessary.

It was decided to set as a foal an $N$ of 240 . It was hoped that an $\mathrm{N}$ of this size would compensate for the lack of ideal precision in contemporary measurement procedures for HS, and that differences which might be missed with a smaller sample would be revealed. This was of particular concern in the search for possible differences in the HS between sexes.

In line with the desire to meet this goal of an $N$ of 240 , it was decided not to seek information from the participants on their drug use patterns. As a residence hall director on the University of Rhode Island campus, the writer was aware of the anxiety that many undergraduate students felt about revealing drug use and of how easily unfounded runors about drug busts and being turned in could be created and spread. The writer did not want potential volunteers to hold back from participation due to any unfounded rumors. So it was decided not to ask any questions on drug use, no matter how confidential the procedures might be. 


\section{Measurement Procedure}

The group-administered Harvard Group Scale of Hypnotic Susceptibility: Form A was chosen as the measurement procedure (Shor and Orne, 1962). Not only would the group administration meet the resource requirements of the study, it had the added and attractive feature of maintaining standardization by being administered through a tape recording (Barber, 1969). And since the writer would be the recruiting person and the experimenter $(E)$ carrying out the measurement procedure, E's voice was used on the tape as well. In this way, a considerable amount of consistency would be maintained.

\section{Statistical Analysis}

The statistical analysis would be a three-way analysis of variance, class $x$ major $x$ sex, and a fixed constants model. The significance level would be set a priori at $\alpha=.05$ (Hays, 1963). Given that the sample was not to be random, significant results would be restricted to the sample itself; and if conclusions were drawn they would be on the basis of the results placed in the context of other studies.

\section{Materials}

Materials required for the study were the following:

1. Manual: HGSHS: A.

2. 300 response booklets, Form A.

3. 3 dozen pencils.

4. Chalk for placing directions on the board.

5. Recruiting form. (Appendix) 
6. Printed post cards used to notify acceptance, time, and place. (appendix)

7. Portable cassette tape recorder and taped procedure.

8. Potential participants list, one for each session.

9. Faculty directory.

10. Tissues (to place contact lenses for those who did not bring their lens case).

\section{Recruitment Process}

In February of 1972, contact was made with various department chairpersons to introduce them to the nature of the study which was about to be undertaken; and to ask their permission to allow $E$ to approach the faculty to ask if $E$ could speak to their classes for a maximum of ten minutes in order to recruit participants for the study. A receptive attitude was met in every case. At least 40 faculty were involved in helping E recruit participants.

After gaining permission to address a class and setting a date to do so, E entered at the beginning of the class and paraphrased the introductory paragraph of the recruiting form (Appendix), passed out the form, explained that the measurement would be done in small groups, answered questions, and attempted to reduce anxiety. While the forms were being filled out, $E$ began to set the desired tone of the study; a tone of non-sensationalism about an experience that would be interesting and worthwhile. And it was explained that their scores would be known to them during the session. While collecting the forms, $\mathrm{E}$ explained that those who met the criteria for the study would be in- 
formed of the time and place of the measurement by a post card, and the class was told approximately when to expect the notification. The recruitment process was very time-consuming and continued constantly until near the end of April of 1972.

When the upper class persons of the art department were sought during the latter phases of the recruiting process, a problem arose. In general, upper class persons were harder to recruit. There were fewer of them, they were to be found in more and smaller classes, and they did not seem as interested to participate. The small informal nature of the arts classes made it even more difficult to contact arts majors. But a seeming stroke of luck placed all the art majors together at one time in a general meeting, and permission was gained to address them. However, there was an apparently well-intended charismatic male member of the group who made it known in a serious and protective plea that he had heard about this study of hypnosis from a trusted friend who knew firsthand that the research was financed by the Federal Gevernment and was part of an effort to gain psychological information about the intellectual community so that the government could exert more effective control over the intellectuals of America. The times were such at the University of Rhode Island that his plea fell on receptive ears, and what $E$ said about the real nature of the study was not believed by the group. Consequently, upper class art majors refused to participate, and the creative arts majors had to be dropped from the study. It was too late to begin recruiting humanities majors to replace them, so in the remaining time, an effort was made to increase the social and natural science majors so that the original 
$\mathbb{N}$ of 240 would be met. The effort was successful and had the advantage of increasing the size of the sub-groups.

During the spring semester of 1972 there was a total of 7,195 undergraduates registered at the University; 4,148 males and 3,147 females. The recruiting process had been met very receptively with only one exception and produced over 1,200 volunteers, of whom 275 met the criteria of the study.

\section{Measurement Sessions}

A classroom that would seat approximately 40 people had been previously reserved for the measurement sessions.

Thirteen one and a half hour measurement sessions (7:00 P.M. to 8:30 P.M.) were conducted during the last two weeks of April and the first week of May, 1972. Initial attempts were made to notify a proportion of the volunteers that would allow for a balance on the factors of class, major, and sex at each session. But it was immediately apparent that the other conmitments of the participants would not make the balance possible. As an alternative procedure, the volunteers were selected at random for assignment to the measurement sessions. Generally, the volunteers were notified of time and place at least four days in advance of the session. If a volunteer did not attend the session, a new time and place post card was mailed that night.

As the participants began arriving, they found E writing on the blackboard the course that the session would follow and engaging in small talk. 
1. Cross out your name on the posted participant list.

2. We will begin at $7: 10$

3. Distribute booklet.

4. Introduction and questions.

5. Measurement procedure.

6. Fill out booklets.

7. General discussion.

Also, a request was written on the blackboard not to chew gum or smoke until after the session was over, and that if anyone was or would soon be under the influence of street drugs, would they please leave, and they would be rescheduled.

Rapport was gradually established with small talk as the participants arrived. After having been in many of the participants' classes doing doing recruitment throughout the semester, E was famiiiar to almost all the participants, and it was not difficult to set people at ease.

The formal session was begun by following the instructions in the manual for establishing rapport. It was also explained that people might be more comfortable if they removed their glasses, but that it was not necessary. People who wore contact lenses were instructed to remove them (tissues were provided to safeguard the lenses for those who did not have their lens case). When it appeared that the pressing questions had been answered and the atmosphere was appropriate, the lighting was dirmed, the measuring procedure was initiated, and the tape recording begun.

In order to minimize sequelae, E utilized the lighting. After the response booklets had been completed and a mood of 'now it is time 
to return to your reference mode of consciousness' had been established, E suggested that "when the lights are turned on, any remaining effects will dissipate, and you will feel fine and fully refreshed." The behavioral responses of the group seemed to indicate that the suggestion had its effects. A discussion followed in order to answer questions that arose as a result of the experience, to ease anxieties, to compare experiences and further educate participants, to look for sequelae, to show them how to determine their scores, and to create a common set for the participants. Part of the set was the idea of avoiding tinkering with hypnosis now that they had experienced it, and making clear that anyone who had any aftereffects was expected to contact $\mathrm{E}$ so that the effects could be eliminated; and a preparation was given on how to handle the natural curiosity of those who had not yet participated in the research so that the study would not be confounded by advanced knowledge of what the procedures were.

Some of the participants brought a roommate or friend with them. A f'ew met the criteria and were incorporated into the study. It appeared that only two people experienced sequelae, one male and one female. During the measurement procedure, the male became obviously disoriented and appeared to be losing his equilibrium. Without disrupting the procedure, $\mathrm{E}$ was able to return him to his reference mode of consciousness by assuring him that his response was nothing to worry about, and that he would be fine as soon as he got himself collected. E then redefined his role and had him help as an observer to watch for others who might have difficulties. After the session, the young man explained that his experience reminded him of 
how he felt when he underwent anesthesia for an operation, a common sequela (Hilgard, 1965). He went home feeling fine. The young lady approached $E$ after the session and explained that she had a headache, another common sequela. E utilized the people present as observers. E's attention was turned to them, and they were talked to as if they were part of a class in which hypnosis was being demonstrated. The young lady's experience was accurately explained to them as something that can happen which need cause no alarm because $E$ was prepared to deal with it. E was intentionally communicating to the young lady through the observers. She gained an understanding of what was happening without $E$ giving her undo focus or defining her headache as a thing to worry about, and the attitude $\mathrm{E}$ created in the group was absorbed by the young lady. Then E turned to the young lady, asked her to close her eyes, gave suggestions to deeply relax as much or even more than she did during the session and then counted backward from 10 to 1 interspersing with suggestions of becoming alert and refreshed. Afterward, the young lady reported feeling fine. She was asked to contact $\mathrm{E}$ if there were any aftereffects.

After each session, the response booklets were placed in folders corresponsing to the group they represented. When there were at least 15 booklets per group, the extra booklets were randomly removed and the remaining 240 booklets were scored. 
CHAPTER IV

RESULTS

Table 1 displays the results of the analysis of variance. The differences across class standing were not significant, nor did inspection show the HS scores to be unusually high (Table 2).

The difference between the HS of natural science majors and social science majors was not significant.

The difference between the HS of males and females was significant; males $=6.44$, S.D. $=2.61$ and females $=7.16$, S.D. $=2.78$. None of the interactions were significant. 
TABLE 1

Analysis of Variance

For Hypnotic Susceptibility

\begin{tabular}{|c|c|c|c|c|}
\hline Source & SS & $d f$ & HS & $\mathrm{F}$ \\
\hline Class (A) & 3.83333 & 3 & 1.27778 & .17135 \\
\hline Major (B) & 8.06667 & 1 & 8.06667 & 1.08174 \\
\hline $\operatorname{Sex}(c)$ & 30.81667 & 1 & 30.81667 & $4.13250 *$ \\
\hline$A X B$ & 15.50000 & 3 & 5.16667 & .69285 \\
\hline$A X C$ & 2.68333 & 3 & 0.89444 & .11994 \\
\hline$B \times C$ & 8.81667 & 1 & 8.81667 & 1.18231 \\
\hline$A \times B \times C$ & 28.28333 & 3 & 9.42777 & 1.26426 \\
\hline $\begin{array}{l}\text { Error } \\
\quad \text { within }\end{array}$ & 1670.39893 & 224 & 7.45714 & \\
\hline Total & 1768.39893 & 239 & & \\
\hline
\end{tabular}


TABLE 2

Mean HS Scores and Standard Deviations

For Class, Major, and Sex

\begin{tabular}{|c|c|c|c|c|c|}
\hline & & $\begin{array}{l}\text { Fresh- } \\
\text { person }\end{array}$ & Sophomore & Junior & Senior \\
\hline \multirow{2}{*}{$\begin{array}{l}\text { Social } \\
\text { Sciences }\end{array}$} & Females & $\begin{array}{c}6.87 \\
(2.67)\end{array}$ & $\begin{array}{c}7.40 \\
(2.56)\end{array}$ & $\begin{array}{c}6.73 \\
(2.66)\end{array}$ & $\begin{array}{c}7.60 \\
(2.92)\end{array}$ \\
\hline & Males & $\begin{array}{c}6.33 \\
(3.04)\end{array}$ & $\begin{array}{c}6.60 \\
(1.96)\end{array}$ & $\begin{array}{c}7.47 \\
(1.92)\end{array}$ & $\begin{array}{c}6.87 \\
(2.30)\end{array}$ \\
\hline \multirow{2}{*}{$\begin{array}{l}\text { Natural } \\
\text { Sciences }\end{array}$} & Females & $\begin{array}{c}7.33 \\
(2.77)\end{array}$ & $\begin{array}{c}7.53 \\
(3.23)\end{array}$ & $\begin{array}{c}7.67 \\
(3.11)\end{array}$ & $\begin{array}{c}6.13 \\
(2.56)\end{array}$ \\
\hline & Males & $\begin{array}{c}6.27 \\
(3.26)\end{array}$ & $\begin{array}{c}6.47 \\
(3.27)\end{array}$ & $\begin{array}{c}5.40 \\
(2.56)\end{array}$ & $\begin{array}{c}6.13 \\
(2.42)\end{array}$ \\
\hline
\end{tabular}

Means stand alone.

Standard Deviations in parentheses.

Mean HS scores were not significant at .05 level. 


\section{CHAPTER V}

\section{DISCUSSION OF THE RESULTS}

\section{Class Standing}

The non-significant results across class standing are interesting. They indicate that for the participants, class standing apparently had no influence on their HS.

Since each class was controlled as much as possible for age, the non-significance for the participants across the classes might lend support to the hypothesis of stabilization of HS during late adolescence and early adulthood, particularly for undergraduate students. However, since it was not possible to recruit enough participants to allow for a large and equal number of participants for each age-grade within each class standing, it is possible that age was not controlled well enough and these and other results were confounded. The results did not appear to reflect any influence of contemporary trends (like the popularization of mind altering chemicals) on HS. The overall mean for the 1972 University of Rhode Island participants was 6.80. Having no other data on University of Rhode Island undergraduates with which to make a comparison, it cannot be determined whether or not 6.80 does represent a significant increase, but it probably does not.

Shor and Orme (1963), in normative work on the HGSHS: A, presented data from a sample of students from Harvard and the vicinity; 
the group mean was 7.39. Two other Harvard Medical School samples had group means of 8.77 and 6.73 . When the 6.80 mean is compared to the results in the literature at large, there is nothing striking about it at all.

\section{Major}

The theoretical position of J. Hilgard (1970) was persuasive to the writer, and there was surprise when the results of the present study were not consistent with J. Hilgard's results. The results of this study might reflect the effects of more control, standardized conditions, and a reasonably good sized sample. It is also possible that lack of difference in HS for the different majors in the present study in no way calls the results from J. Hilgard's (1970) study into question. Perhaps the different majors at Stanford are more different from each other than the different majors in the University of Rhode Island sample. And it is possible that the results were confounded by the age factor. Until the basic research on HS has been done, these problems will remain unresolved.

\section{$\underline{\text { Sex }}$}

Although the difference between the HS of males and females was significant, this result must be viewed with caution. Even though there were numerous controls with a large $N$, other explanations for the results are possible. It is possible, for example, given the number of $F$ tests in the analysis of variance, that the one showing significance for sex differences was a consequence of chance. And 
again, age effects might have been confounding.

Given the above results it is not surprising that there were no interaction effects. 
CHAPTER VI

\section{CONCLUSIONS}

"...most of the world's knowledge is based on samples, probably most often on inadequate samples." Kerlinger, 1964

An attempt to use a random sample to investigate the basic variables of class standing, major, and sex, and their relationship to HS probably would not have surfaced enough participants to allow for a meaningful analysis. As an alternative, a serious effort was made to develop an adequate, selected sample based on specific criteria, from which the results could then be analyzed with a robust technique. With this approach, the initial phase of long needed basic research on HS could be completed within the population regularly used for HS research. It is believed that the limited goals of this research have been achieved.

It needs to be stated explicitly that conclusions drawn from the results of a selected sample, unlike a random sample, cannot be generalized. The results from a selected sample of undergraduate students cannot be generalized to all undergraduate students or to people in general. At best, the results from a selected sample reflect the characteristics of the select population from which it comes. 
Since this research is basic research designed to search for evidence of the relationship between certain variables and $\mathrm{HS}$, the restriction of non-generalizability is acceptable (Kerlinger, 1973).

The analysis of the HS of the 240 participants suggested that class standing and major did not have a bearing on their HS, but that their sex did. However, designs and analyses have their limitations, and the possibility of chance factors and the influence of inadequately controlled and extraneous variables cannot be ruled out as the prime movers behind the results. It is possible that age was not controlled well enough. Afterall, enough people could not be recruited in order to have each age-grade represented equally for each class standing; there were not enough volunteers who met the criteria to have an equal number of 21 and 22 year olds in the senior class standing. Consequently, it cannot be concluded that the results for this sample clearly demonstrate that there were no differences in HS across the undergraduate class standings. Perhaps other research efforts will be able to more effectively control for age and offer more conclusive evidence.

One can only speculate what the results for major might have been if the creative arts or humanities majors could have been included. Perhaps on the University of Rhode Island campus science students, regardless of whether natural or social, are similar for HS in ways creative arts students are not. More research is necessary in order to unravel the issue.

It is possible that the significant difference between the sexes for HS was a chance happening. The absolute difference was not 
quite 1 point on a 12 point scale. But then, volunteers tend to have higher levels of HS, and male and female volunteers might be more similar for HS than would males and females from a non-volunteering population. And of course, there are the measurement procedures; although they are the best we have, they are not as precise, perhaps, as we would wish. And there is the possibility of age confounding. Theory on sex and HS has undergone a polar shift from the nineteenth century conception of females being markediy susceptible relative to males to the contemporary conception of equality of $\mathrm{HS}$ for the sexes. Perhaps this theoretical shift reflects actual changes in HS, which have resulted from social changes, although Liébeault's results of little difference in the HS of males and females calls this into question. Perhaps the theoretical shift actually reflects changes in attitudes toward the sexes, rather than changes in HS levels. Hopefully, more effectively designed research will help solve the matter.

A potentially fruitful approach to the issue of sex and HS would be to recruit and assess the HS of male and female undergraduate volunteers $(N=200+)$ who are equally balanced for age and represent a single class standing. In order to achieve the desired $\mathrm{N}$, major might have to be de-emphasized. Repeating this approach for each class standing under similar standardized conditions might produce results that would be conclusive. If this approach were repeated several times, it might also clarify the matter of relative differences across class standing. And a pooling of all the data might add useful information concerning major and HS. 
This research certainly has not clarified any issues or resolved any basic problems. But it is a beginning; a beginning in an effort to assess the basic variables relevant to the HS of undergraduate students, the single largest group of people in this country with whom HS research is carried out. The main conclusion of the present research is that more ground work needs to be covered before we can say with confidence that we know what the basic variables are that influence HS. And we have still more to do before we can say with any confidence why the variables work the way they do. 
APPENDIX 
RECRUITMENT FORM

People are needed to participate in a study that is being conducted within the psychology department. The study is concerned with the assessment of hypnotic susceptibility. Each person's experience will consist of having his or her susceptibility to hypnosis measured. Those who wish to participate and meet the following criteria are invited to join the study.

1. U. R. I. undergraduate

2. Continuous enrollment since freshman year

3. Natural born citizen

4. Unmarried

Name:

Address:

Class: Fresh
Age: $\quad$ Sex: $M F$

Phone:

Senior

Formal major or anticipated major:

Primary personal academic interest area (example-organic chemistry, acting, English history, etc.):

Please return this form to your participating professor or return it directly to the secretary in the Psychology Department. If we can schedule you, you will be contacted so that we can make time and place arrangements. If you know anyone else who would like to participate, have him or her call the secretary in the Psychology Department during the day (792-2193) or the study director during the early evening (792-2024) and give the above information. 


\section{POST CARD}

\section{Hypnotic Susceptibility Study}

\section{Place: Independence $\mathrm{Hall}$ \\ Day: \\ Time:}

Room 208

You participation in this study is truly appreciated. Without your help the study simply could not be done.

If it is not possible for you to attend at the above time, you will be rescheduled for another time. If by the third card you find that you are still unable to attend, please call 792-2024 between 5:00 and 6:00 P.M. so we can make other arrangements. However, try to come at the above time so that we can avoid a "scheduling back-log." 
REFERENCES

Alpert, R., Cohen, S., and Schiller, L. LSD. N.Y.: The New American Library, 1966.

As, A., Hilgard, E. and Weitzenhoffer, A. An attempt at experimental modification of hypnotizability through repeated individualized hypnotic experience. Scandinavian Journal of Psychology, 1963 4, 81-89.

Aveling, F. and Hargreaves, H. Suggestibility with and without prestige in children. British Journal of Psychology, 1921-22, $\underline{12}, 53-75$.

Baernstein, L. An experimental study of the effect of small doses of scopolomine hydrobromide. Thesis submitted for M.A. degree, 1929.

Barber, T.X. Hypnosis: A Scientific Approach. N.Y.: Van Nostrand Reinhold Company, 1969.

Barber, T.X. LSD, Mari,juana, Yoga, and Hypnosis. Chicago: Aldine Publishing Co., 1970.

Barber, T., Ascher, L. and Mavroides, M. Effects of practice on hypnotic suggestibility: a re-evaluation of Hull's postulates. American Journal of Clinical Hypnosis, 1971, 1, 48-53.

Barber, T. and Calverley, D. "Hypnotic-like" suggestibility in children and adults. Journal of Abnormal and Social Psychology, 1963, 66, 589-97.

Barber, T. and Calverley, D. Toward a theory of hypnotic behavior: experimental evaluation of Hull's postulate that hypnotic susceptibility is a habit phenomenon. Journal of Personality, 1966, 24, 416-433.

Barry, H., Mackinmon, D., and Murry, H. Studies in personality: a. hypnotizability as a personality trait and its typological relations. Human Biology, 1931, 2, 1-36.

Baudelaire, C. The Poem of Hashish. N.Y.: Harper \& Rowe, Publishers, 1971.

Bentley, M. and Roberts, R. Hypnotic susceptibility assessed in large groups. International Journal of Clinical and Experimental Hypnosis, $1963,11,93-97$. 
Bernheim, H. Hypnosis and Suggestion. N.Y.: University Books, 1964.

Boucher, R. and Hilgard, E. Volunteer bias in hypnotic experiments. American Journal of Clinical Hypnosis, 1962, 2, 49-51.

Brady, J., Levitt, E. and Lubin, B. Expressed fear of hypnosis and volunteering behavior. Journal of Nervous and Mental Disorders, $1961,133,216-217$.

Brown, W. Individual and sex differences in susceptibility. University Publications in Psychology, 1916, 2, 291-430.

Buros, O.K. (Ed.) The Sixth Mental Measurements Yearbook. Highland Park, N.J.: Gryphon Press, 1965.

Cason, H. Influence of imagery in a group situation. Journal of Abnormal and Social Psychology, 1925, 20, 294-299.

Coe, W. Further norms on the Harvard Group. Scale of Hypnotic Susceptibility: Form A. International Journal of Clinical and Experimental Hypnosis, $1964,11: 3,184-190$.

Cooper, L., Banford, S., Schubot, E., and Tart, C. A further attempt to modify hypnotic susceptibility through repeated individualized experiences. International Journal of Clinical and Experimental Hypnosis, 1967, 15(3), 118-124.

Cooper, L. and London, P. Sex and hypnotic susceptibility in children. The International Joumal of Clinical and Experimental Hypnosis, 1966, 14:1, 55-60.

Davis, I. and Husband, R. A study of hypnotic susceptibility in relation to personality traits. Journal of Abnormal and Social Psychology, 1931, 26, 175-182.

DeBold, R. and Leaf, R. LSD, Man and Society. Connecticut: Wesleyan University Press, 1967.

Eysenck, H. Suggestibility and hysteria. Journal of Neurological Psychiatry, $1943,6,22-31$.

Fisher, S. Body image and hypnotic response: The International Journal of Clinical and Experimental Hypnosis, 1963, 11:3, 152-162.

Fogels, S. and Hoffer, A. The use of hypnosis to interrupt and to reproduce an LSD-25 experience. Journal of Clinical and Experimental Psychopathology, 1962, 23, 11-16. 
Friedlander, J. and Sorbin, R. The depth of hypnosis. Journal of Abnormal Social Psychology, 1938, 33, 281-294.

Gill, M. and Brenman, M. Hypnosis and Related States. N.Y.: John Wiley and Sons, Inc., 1959.

Grinspoon, L. Marijuana Reconsidered. Cambridge, Massachusetts: Bantam Books, 1971.

Haley, J. (Ed.) Advanced Techniques of Hypnosis and Therapy: Selected Papers of Milton H. Erickson, M.D. N.Y.: Grune \& Stratton, 1967.

Hays, W. Statistics. N.Y.: Holt, Rinehart, and Winston, 1963.

Hilgard, E. Hypnotic Susceptibility. N.Y.: Harcourt, Brace \& World, 1965.

Hilgard, E. and Lauer, L. Lack of correlation between the California psychological inventory and hypnotic susceptibility. Journal of Consulting Psychology, 1962, 26, 331-335.

Hilgard, J. Personality and Hypnosis. Chicago: University of Chicago Press, 1970.

Hull, C. Hypnosis and Suggestibility. N.Y.: Appleton-CenturyCrofts, 1933.

Huxley, A. The Doors of Perception. N.Y.: Harper \& Rowe, 1954.

Huxley, A. Heaven and Hell. N.Y.: Harper and Rowe, 1955.

Kerlinger, F. Foundations of Behavioral Research. N.Y.: Holt, Rinehart, \& Winston, 1964, 1973.

Levis, D. and Menlman, B. Suggestion and mescaline sulphate. Journal of Neuropsychiatry, $1964,5,193-200$.

Levitt, E. and Lubin, B. The effect of incentives on volunteering for an hypnosis experiment. International Journal of Clinical and Experimental Hypnosis, $1962,10,39-41$.

Lindesmith, A. (Ed.) The Marijuana Papers. N.Y.: The New American Library, Publishers, 1966.

Lodge, J. The illusion of warmth test for suggestibility. Forum for Education, 1926, 2, 180-186. 
London, P. Hypnosis in children: an experimental approach. International Journal of Clinical and Experimental Hypnosis, $1962,10,79-91$.

London, P. The Children's Hypnotic Susceptibility Scale: I. California: Consulting Psychologists Press, 1963.

London, P. Developmental experiments in hypnosis. Journal of Projective Technioues and Personality Assessment, 1965, 29 , $189-199$.

Manzer, C. The effect of verbal suggestion on output and variability muscular work. Psychology Clinic, 1945, 35, 163-166.

Martin, R. and Marcuse, F. Characteristics of volunteers and nonvolunteers for hypnosis. Journal of Clinical and Experimental Hypnosis, $1957,2,176-180$.

Masters, R. and Houston, J. The Varieties of Psychedelic Experience. N.Y.: Dell Publishing Co., 1966.

McGeogh, J. The relationship between suggestibility and intelligence in delinquents. Psychology Clinic, 1925, 16, 133-134.

Melei, J. and Hilgard, E. Attitudes toward hypnosis, self-predictions, and hypnotic susceptibility. International Journal of Clinical and Experimental Hypnosis, $1964,12(2), 99-108$.

Messerschmidt, R. A Suggestibility Scale. Ohio State University: Masters Thesis, 1927.

Messerschmidt, $R$. Response of boys between the ages of five and six to Hull's postural suggestion test. Journal of Genetic Psychology, 1933a, 43, 405-421.

Messerschmidt, $R$. The suggestibility of boys and girls between the ages of six and sixteen years. Journal of Genetic Psychology, $1933 b, 43,422-437$.

Morgan, A. Personal correspondence with Dr. Stanley Berger, Psychology Department, University of Rhode Island, Kingston, Rhode Island, 1970.

Morgan, A. Personal correspondence with Dr. Stanley Berger, Psychology Department, University of Rhode Island, Kingston, Rhode Island, 1971.

Morgan, A. and Hilgard, E. Age differences in susceptibility to hypnosis. Manuscript, 1971. 
Morgan, A. and Hilgard, E. Age differences in susceptility to hypnosis. International Journal of Clinical and Experimental Hypnosis, 1973, 21, 78-85.

Moore, R. and Lauer, L. Hypnotic susceptibility in middle childhood. International Journal of Clinical and Experimental Hypnosis, $1963,11,167-174$.

Morgan, A. and Williams, D. Hawthorne House research memorandum \#10, private circulation only, not for publication, 1970.

Nowlis, H. Drugs on the College Campus. N.Y.: Doubleday \& Company, Inc., 1969.

Otis, M. Study of suggestibility in children. Archives in Psychology, 1924,20 .

Pascal, G. and Salzberg, H. A systematic approach in inducing hypnotic behavior. International Journal of Clinical and and Experimental Hypnosis, 1959, 1, 161-167.

Rhoades, C. and Edmonston, W. Personality correlates of hypnotizability: a stuay using the Harvard Group Scale of Hypnotic Susceptibility, the 16-F and IPAT. American Journal of Clinical Hypnosis, $1969,11,228-233$.

Roach, J. An experimental study of suggestibility in extroverts and introverts. Journal of Applied Psychology, 1941, 25, 458-68.

Rosenhan, D. and Tomkins, S. On preference for hypnosis and hypnotizability. International Journal of Clinical and Experimental Hypnosis, 1964, 12, 109-114.

Sachs, L. and Anderson, W. Modification of hypnotic susceptibility. International Journal of Clinical and Experimental Hypnosis, $1967,15(4), 172-180$.

Sanders, R. and Reyher, J. Sensory deprivation and the enhancement of hypnotic susceptibility. Journal of Abnormal Psychology, 1969, 74, 374-381.

Seashore, E. Measurements of illusions and hallucinations in normal life. Studies of the Yale Psychology Laboratory, 1895, 2, 1-67.

Shor, R. and Cobb, J. An exploratory study of hypnotic training using the concept of plateau responsiveness as a referent. American Journal of Clinical and Experimental Hypnosis, 1968, 10(3), $178-193$. 
Shor, R. and Orne, E. Harvard Group Scale of Hypnotic Susceptibility, Form A. California: Consulting Psychologist Press, 1962.

Shor, R. and Orne, E. Norms of the Harvard Group Scale of Hypnotic Susceptibility, Form A. The International Journal of Clinical and Experimental Hypnosis, 1963, 11:1, 39-47.

Shor, R., Orne, M., and O'Connell, D. Validation and cross-validation of a scale of self-reported personal experiences which predicts hypnotizability. Journal of Psychology, 1962, 23, 55-75.

Stukat, K. Suggestibility: A Factorial and Experimental Analysis. Stockholm: Almquist and Wiksell, 1958.

Tart, C. Altered States of Consciousness. N.Y.: John Wiley \& Sons, Inc., 1969.

Tart, C. On Being Stoned: A Psychological Study of Marijuana Intoxication. California: Science \& Behavior Books, 1971.

Van Nuys, D. Drug use and hypnotic susceptibility. International Journal of Clinical and Experimental Hypnosis, 1972, 20(1), 31-37.

Vogel, V. Suggestibility in narcotic addicts. Public Health Report and Supplement, $1937,132$.

Watts, A. The Joyous Cosmology. N.Y.: Random House, 1962.

Wegrecki, H. The effect of prestige suggestibility on emotional attitudes. Journal of Social Psychology, 1934, 5, 384-394.

Weil, A. The Natural Mind: A New Way of Looking at Drugs and the Higher Consciousness. Boston: Houghton Mifflin Company, 1972.

Weitzenhoffer, A. Hypnotism. N.Y.: Wiley \& Sons, 1953.

Weitzenhoffer, A. General Techniques of Hypnosis. N.Y.: Grune \& Stratton, 1957.

Weitzenhoffer, A. and Hilgard, E. Stanford Hypnotic Susceptibility Scale, Form A \& B. California: Consulting Psychologist Press, 1959.

Weitzenhoffer, A. and Hilgard, H. Stanford Hypnotic Susceptibility Scale: Form C. California: Consulting Psychologist Press, 1962. 
Weitzenhoffer, A. and Weitzenhoffer, G. Sex, transference, and susceptibility to hypnosis. American Journal of Clinical Hypnosis, 1958, 1, 15-24.

Wickramsekera, I. Effects of sensory restriction of susceptibility to hypnosis: a hypothesis, some preliminary data, and theoretical speculation. International Journal of Clinical and Experimental Hypnosis, $1969,17(4), 217-224$.

Wiseman, R. and Rehyer, J. Procedure utilizing dreams for deepening the hypnotic trance. American Journal of Clinical Hypnosis, $1962-63,5,105-110$.

Zamansky, H. and Brightbill, R. Attitude differences of volunteers and non-volunteers and non-susceptible hypnotic subjects. International Journal of Clinical and Experimental Hyonosis, $1962,4,229-290$. 